\title{
Current Approaches to the Treatment of Gastroesophageal Reflux Disease in Children with Neurology
}

\author{
Nurlan Nurkinovich Akhparov ${ }^{1}$, Riza Zulkarnaevna Boranbayeva ${ }^{2}$, \\ Saule Bakhtyarovna Suleimanova ${ }^{3}$, Vasiliy Mikhailovich Lozovoy ${ }^{3}$ \\ ${ }^{1}$ Department of Surgery, Scientific Center of Pediatrics and Pediatric Surgery, Almaty, Republic of Kazakhstan \\ ${ }^{2}$ Department of Pediatrics, Scientific Center of Pediatrics and Pediatric Surgery, Almaty, Republic of Kazakhstan \\ ${ }^{3}$ Pediatric Surgery Chair, Medical University Astana, Astana, Republic of Kazakhstan
}

\section{Email address:}

saule_suleiman@mail.ru (S. B. Suleimanova)

\section{To cite this article:}

Nurlan Nurkinovich Akhparov, Riza Zulkarnaevna Boranbayeva, Saule Bakhtyarovna Suleimanova, Vasiliy Mikhailovich Lozovoy. Current Approaches to the Treatment of Gastroesophageal Reflux Disease in Children with Neurology. American Journal of Pediatrics.

Vol. 5, No. 1, 2019, pp. 14-17. doi: 10.11648/j.ajp.20190501.13

Received: January 10, 2019; Accepted: February 14, 2019; Published: March 5, 2019

\begin{abstract}
The incidence of gastroesophageal reflux in children with neurological disorders is more common than in the rest of the pediatric population. The risk of reflux development in these children is due to abnormal motility of the gastrointestinal tract, their long term staying in bed (a horizontal position), a disruption of the swallowing process, a delayed evacuation of food from the esophagus and stomach, and a weakened muscle tone that pose a serious threat to a patient by possible complications (such as reflux esophagitis, peptic stricture, erosion and bleeding), and sometimes being one of the causes of death. From 2008 to 2018, 128 patients with gastroesophageal reflux disease were hospitalized in the Department of Surgery of the Scientific Center for Pediatrics and Pediatric Surgery including 33 (26\%) children with neurological disorders, of which 28 (85\%) were operated. All of the patients underwent Nissen esophagofundoplications, of which in $21(75 \%)$ children it was combined with Stamm gastrostomy and in 18 (64\%) children with Mikulich pyloroplasty. The results of surgical treatment were analysed in all the 28 patients in the early period (7-14 days) after surgery. In 2 (7\%) children who did not undergo the pyloroplasty there was a complication in the form of gastric distress syndrome, which required an additional surgery in order to drain the stomach. A relapse of gastroesophageal reflux disease was observed in $1(4 \%)$ patient who was re-operated. In the remaining $25(89 \%)$ children, the postoperative period was favourable. Their gastrostomy tube feeding was carried out according to the age requirements. The long-term results were studied in time interval from 6 months to 3 years after surgery. $\mathrm{X}$-ray control examination, fibroendoscopy and 24 -hour $\mathrm{pH}$ monitoring were conducted in all children in the distant period. The results of the treatment are favourable, the weight deficit is filled, the reflux esophagitis is stopped and the refluxassociated inflammations of the bronchopulmonary system are reduced. To a large extent, the choice of operational tactics can be adapted to the condition of a particular child, the results of objective and instrumental tests for GERD, the pseudobulbar disorders and associated pyloric functional disorders. Timely correction of reflux disorders in children with pathologies of the central nervous system helps prevent the development of serious complications, which will inevitably improve a child's quality of life.
\end{abstract}

Keywords: Gastroesophageal Reflux, Neurology, Children

\section{Introduction}

The diagnosis of gastroesophageal reflux in children with neurological disorders is rather complicated due to the missing characteristic features of this disease. Moreover, the diagnosis is affected by the objective difficulties of examination, problems in communicating with the patient and by the atypical symptoms (such as anxiety, dystonia, convulsions, etc.) [1]. A gastroesophageal reflux should be considered in a child under the overall assessment of such symptoms as frequent episodes of pneumonia, choking and recurrent respiratory infection. 
Problems of swallowing as a result of bulbar disorders lead to direct aspiration of food from the oropharynx and hypopharynx and cause chronic respiratory infections. A reduced or missing cough reflex also makes the contents of the oral cavity and pharynx getting to the lungs. In most cases, children with neurological disorders have a certain degree of swallowing dysfunction, which can lead to oropharyngeal aspiration. These patients may aspirate the gastric contents along with the saliva during feeding. An alternative way to prevent respiratory distress often means avoiding oral feeding (for example, feeding through a gastrostomy tube) [2].

We present our experience in treating children with gastroesophageal reflux disease in the central nervous system pathology structure.

\section{Materials and Methods}

From 2008 to 2018, the gastroesophageal reflux disease was diagnosed and treated in 128 of the Department of Surgery of the Scientific Center for Pediatrics and Pediatric Surgery. Of this number, $33(26 \%)$ children had central nervous system disorders. The children's age ranged from 2 months to 12 years old. The patient profile was represented by 14 children with birth trauma ( $42 \%$ cases), 19 children with cerebral palsy $(58 \%), 21$ child with cerebral palsy in combination with pseudobulbar disorders (64\%) and 12 children with neurogenic dysfunction of the esophagus $(36 \%)$.

In $100 \%$ of cases, vomiting was a leading symptom of nutritional disorders along with the clinical manifestations of pseudobulbar dysfunctions (hypersalivation, microaspiration with saliva) and a progressive weight loss tendency. In 19 (58\%) patients, feeding through a nasogastric tube was carried out from their first days of life. The children did not receive any adequate nutrition, while the attempts to increase the volume of a single feeding led to an increased frequency of emetic manifestations, which resulted in their physical development lagging behind and body weight loss. Thus, the $1^{\text {st }}$ degree hypotrophy was observed in 10 children $(30 \%$ cases), the $2^{\text {nd }}$ degree hypotrophy occurred in 16 (48\%) cases, and in $7(22 \%)$ cases the deficiency of body weight exceeded $20 \%$. Respiratory complications prevailed along with the clinical symptoms of eating disorders. Long-term inpatient treatment in the pulmonology departments for protracted reflux-induced pneumonia was received by 21 (64\%) patients, for the night cough manifestations by $18(55 \%)$ patients, and in most cases a combination of these symptoms was noted. 16 (48\%) children had a history of apnea.

The $1^{\text {st }}$ degree anemia was diagnosed in $17(52 \%)$ cases and in $12(36 \%)$ children anemia of the 2 nd degree was diagnosed.

Primary diagnostic measures used in order to study the features of this pathology were aimed at examining the anatomical and functional state of the esophagus, elements of the esophago-gastric junction and the stomach, including fibroendoscopy with a pinch biopsy of the esophageal mucosa, pH-metry, ultrasonography of the stomach, X-ray and refluxate cytology.

\section{Results}

The endoscopic view of the severity of esophagitis was evaluated according to the Savary-Miller classification. Thus, the 2nd degree esophagitis was identified in $8(24 \%)$ children whereas the $3^{\text {rd }}$ degree was revealed in $6(18 \%)$ and esophagitis of the $4^{\text {th }}$ degree was found in $3(9 \%)$ (Figure 1).

A daily $\mathrm{pH}$ monitoring revealed a predominantly acid reflux in $19(58 \%)$ children and an acid-based combined reflux in $6(18 \%)$. The most pronounced exposure to acid reflux was observed at night. The ultrasound examination revealed the distal esophagus walls thickening and its deformation, while the lumen of the esophagus gaped even beyond the child's feeding time. In all $100 \%$ of cases, a pendulum-like turbulent movement of contents from the cavity of the stomach into the esophagus was observed (Figure 2). It was necessary to comprehensively examine the gastro-duodenal transition in the pathology of the esophagus and stomach of the neurological children. As a result of the study, various dysfunctions of the stomach motility and duodenum were found, one of the signs of which was an increase in the size of the stomach in $18(55 \%)$ children, which in our opinion was due to a functional pyrolospasm

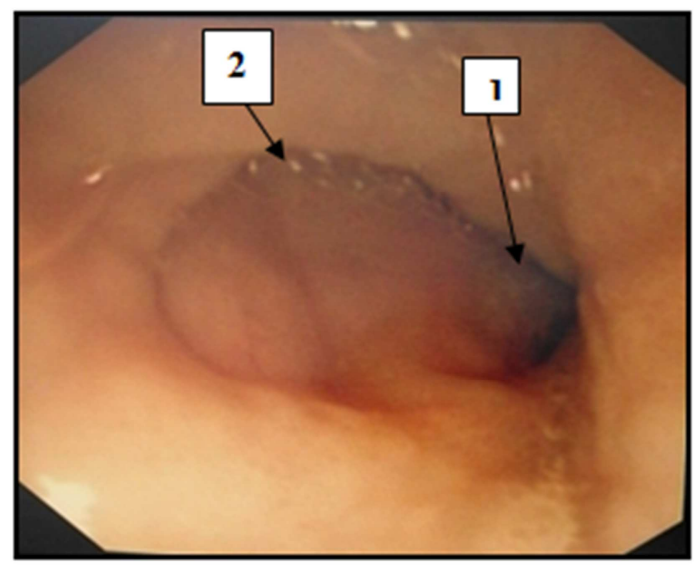

Figure 1. Fibrinous and erosive esophagitis. Fibroesophagogastroscopy.1 expansion of the cardiac outlet; 2 - eccentric cardiac sphincter session.

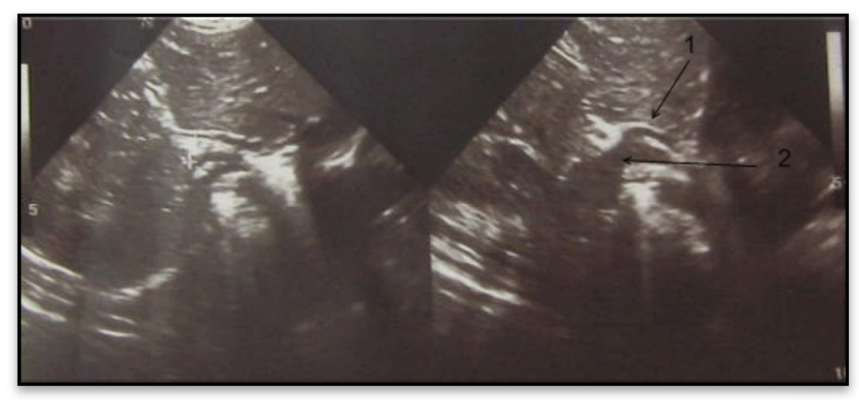

Figure 2. Cardiac sphincter insufficiency Ultrasonography of the esophagus and stomach: 1 - the walls of the distal esophagus are thickened, the mucous membrane is swollen; 2 - expansion of the gastroesophageal sphincter zone. 
An X-ray view showed a secondary megaesophagum in 26 (79\%) children. In a Trendelenburg position, the reflux-refusal of the $1^{\text {st }}$ degree was identified in 5 children $(15 \%)$, that one of the $2^{\text {nd }}$ degree in 13 children $(40 \%)$, and in $15(45 \%)$ cases the reflux-refusal of the $3^{\text {rd }}$ degree was revealed (Figure 3 ). Evacuation from the stomach was slowed down in $18(55 \%)$ patients with varying degrees of severity.

We have proposed a method for the diagnosis of gastroesophageal reflux disease (AC 2012/0614.1). In addition to the existing radiological symptoms, it is necessary to pay attention to increased gas filling in the esophageal cavity. A large number of heterogeneous polymorphic gas bubbles in the composition of the contrast when filling the esophageal tube suggest a pathological pneumonia of the esophagus, which in our opinion, is pathogenic to verify the diagnosis, which was detected in $22(67 \%)$ children (Figure 4$)$.

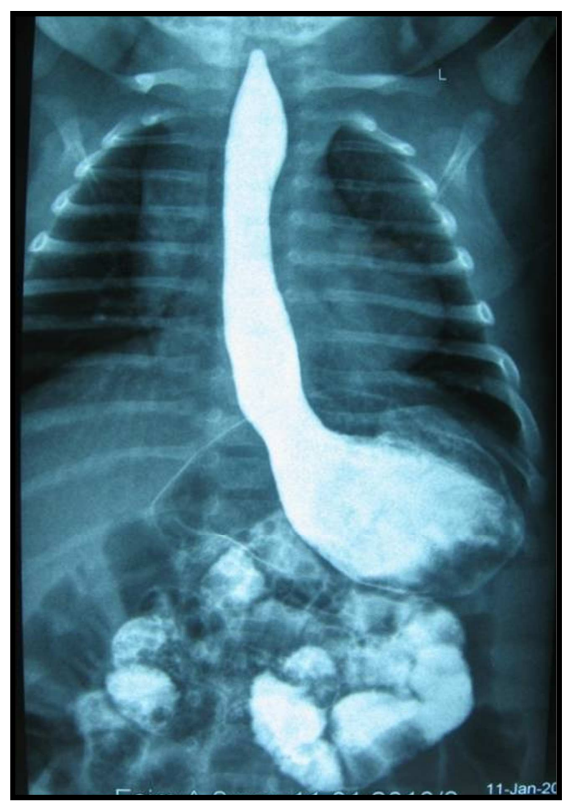

Figure 3. Reflux-throwing of the 3rd degree. Esophagography in a Trendelenburg position.

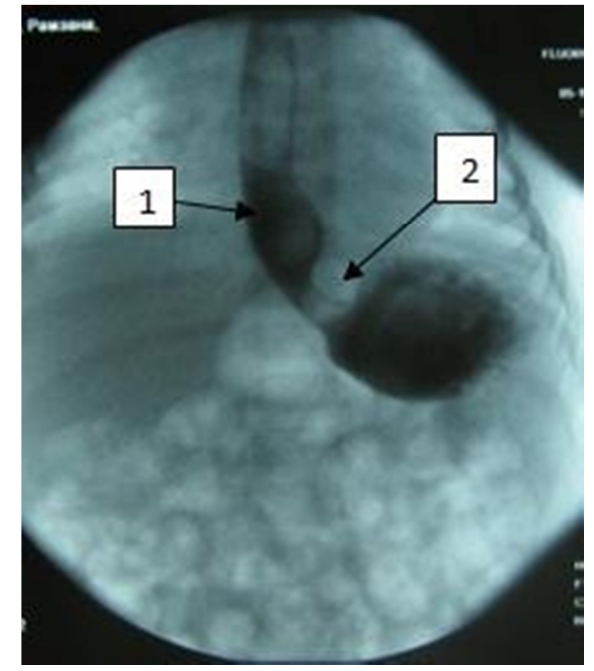

Figure 4. "Pneumatosis" of the esophagus lumen. Esophagography: 1 pneumatosis of the esophagus lumen; 2 - increasing the angle of His to 110 degrees.
An integrated approach to the diagnosis of gastroesophageal reflux disease and the degree of neurogenic dysfunction of the gastrointestinal tract motility in children with the central nervous system disorders made it possible in all cases to clear out and individualize the indications for palliative surgery.

$28(85 \%)$ out of 33 children with gastroesophageal reflux disease in the central nervous system pathology structure were operated. All the patients underwent Nissen esophagofundoplications, of which in $21(75 \%)$ children it was combined with the Stamm gastrostomy and in 18 (64\%) with Mikulich pyloroplasty.

The results of surgical treatment were analysed in all the 28 patients in the early period (7-14 days) after surgery. In 2 (7\%) children who did not undergo the pyloroplasty there was a complication in the form of gastric distress syndrome, which required an additional surgery in order to drain the stomach. A relapse of gastroesophageal reflux disease was observed in $1(4 \%)$ patient who was re-operated. In the remaining $25(89 \%)$ children, the postoperative period was favourable. Their gastrostomy tube feeding was carried out according to the age requirements.

\section{Discussion}

Severe chronic GERD development in children with the nervous system pathology is of a multifactor nature. A prolonged horizontal position, impaired swallowing, delayed evacuation of food from the stomach, constipation, skeletal abnormalities, impaired muscle tone and side effects of the used drugs altogether contribute to a high reflux rate and slow down the esophageal clearance. In addition, the severity of GERD may be due to the lack of protective antireflux mechanisms [3].

It is suggested to include measures for changing the lifestyle and nutrition modes in the treatment of children with the nervous system pathology and concomitant GERD, which will depend on a patient's risk factors. Thus, the researches of Miele E., Staiano A. and Tozzi A. showed the improvement of GERD symptoms resistant to therapy against the amino acid mixture usage [4]. An alternative to effective treatment of this group of patients may be changes in the consistency of food, its volume and frequency of administration as well as postural therapy. The antisecretory therapy in the optimal regimen and doses meeting the international recommendations is prescribed in the research paper by Vandenplas Y., Rudolph C. D., DiLorenzo C. et al. [5].

Hassall E., Kerr W. et al. state that a long term treatment with proton pump inhibitors can be effectively used in children with neurological disorders upon demand and in order to maintain remission in esophagitis [6].

Current methods of medical treatment of GERD can prolong clinical remission and shorten the healing time of focal esophageal inflammatory lesions [7]. However, despite the high level of modern drug therapy, its effect is temporary. A drug withdrawal is followed by the symptoms recurring in $50 \%$ of patients after 6 months and in $100 \%$ after 12 months, 
which requires constant long-term maintenance therapy [8].

Nowadays, surgical methods of GER treatment are widely used, especially being facilitated by the laparoscopic surgery development $[9,10,11,12]$.

According to the paper by E. W. Fonkalsrud, A. G. Coran and K. W. Ashcraft (1998) fundoplication is conducted in up to $40 \%$ children with severe neurological disorders, manifested by constant vomiting and aspiration syndrome. In these patients, the gastroesophageal reflux occurs more frequently than in the rest of the pediatric population, which is accompanied by an increased risk of adverse complications, a return of reflux symptoms and death [13].

This was previously reported by the research authors $\mathrm{S}$. Berezin, S. M. Schwarz and M. S. Halata (1986), who demonstrated that neurologically weakened babies had a lower pressure in the lower esophageal sphincter that predisposed both reflux and a recurrent respiratory infection [14].

Data from a US national study show that $45 \%$ of antireflux procedures are performed on the children under 1 year [15]. The profile of patients in this age group also includes infants with impaired swallowing and aspiration against the lesion of the nervous system. The risk of gastroesophageal reflux in these infants is due to the pathological motility of the gastrointestinal tract and anomalies of the gastroesophageal junction.

\section{Conclusion}

1). A comprehensive approach to timely verification of gastroesophageal reflux disease in children with disorders of the central nervous system will in all cases allow to individualize the indications for palliative surgery.

2). In children with neurological disorders (bulbar disorders), it is advisable to supplement anti-reflux surgery with gastrostomy.

3). In children of this group without indications for gastrostomy, it is advisable to combine fundoplication with pyloroplasty, which helps prevent the development of gastric distress syndrome and thus avoid repeated operations.

4). The study of long-term results suggests that an individual approach to the choice of treatment for GERD can prevent the development of serious complications, which will inevitably affect the quality of life of the child.

5). Understanding the potential gastrointestinal motility disorders associated with GERD in these patients is necessary for a realistic assessment of the expectations of child's parents.

\section{References}

[1] Gossler A., Schalamon J., Huber-Zeyringer A. et al. Gastroesophageal reflux and behavior in neurologically impaired children. J Pediatr Surg., 2007, vol. 42. - P. 1486-90.
[2] Morton R. E., Wheatley R., Minford J. Respiratory tract infections due to direct and reflux aspiration in with severe neurodisability. Dev. Med. Child. Neurol. 1999; 41: 329-34.

[3] Pensabene L., Miele E., Giudice E. D. et al. Mechanisms of gastroesophageal reflux in children with sequelae of birth asphyxia // Brain Dev. — 2008. — Vol. 30. - P. 563-71.

[4] Miele E., Staiano A., Tozzi A. et al. Clinical response to aminoacid-based formula in neurologically impaired children with refractory esophagitis // J Pediatr Gastroenterol Nutr. 2002. - Vol. 35. - P. 314-9.

[5] Vandenplas Y., Rudolph C. D., Di Lorenzo C. et al. Pediatric Gastroesophageal Reflux Clinical Practice Guidelines: Joint Recommendations of the North American Society for Pediatric Gastroenterology, Hepatology, and Nutrition (NASPGHAN) and the European Society for Pediatric Gastroenterology, Hepatology, and Nutrition (ESPGHAN) // Journal of Pediatric Gastroenterology and Nutrition. - 2009. — Vol. 49. - P. 498-547.

[6] Hassall E., Kerr W., El-Sera HB. Characteristics of children receiving proton pump inhibitors continuously for up to 11 years duration // J Pediatr. — 2007. — Vol. 150. — P. 262.

[7] Hassall, E. Decisions in diagnosing and managing chronic gastroesophageal reflux disease in children/ E. Hassall // J. Pediatr. - 2005. - Vol. 146, № 1. - P. 3-12.

[8] Guimaraes, E. Treatment of gastroesophageal reflux disease / E. Guimaraes, C. Marguet, P. Camargos // J. Pediatr. - 2006. Vol. 82, № 5. - P. 133-145.

[9] Razumovsky, A. Yu. Laparoscopic fundoplication - a radical method of treating gastroesophageal reflux in children / A. Yu. Razumovsky, A. B. Alkhasov, V. E. Rachkov // Pediatrics. 2006. - № 5. - P. 57.

[10] Lobe, T. The current role of laparoscopic surgery for gastroesophageal reflux disease in infants and children / $\mathrm{T}$. Lobe // Surg. Endosc. - 2007. - Vol. 21, № 2. - P. 167-174.

[11] Kane, T. D. Position paper on laparoscopic antireflux operations in infants and children for gastroesophageal reflux disease. American Pediatric Surgery Association / T. D. Kane, M. F. Brown, M. K. Chen // J. Pediatr. Surg. - 2009. - Vol. 44, № 5. - P. 1034-1040.

[12] Tovar, A. J. Pediatric surgeons and gastroesophageal reflux / A. J. Tovar, L. A. Luis, L. J. Encinas // J. Pediatr. Surg. 2007. - Vol. 42. - P. 277-283.

[13] Fonkalsrub, E. W. Antireflux surgery in children under 3 months of age / E. W. Fonkalsrub, J. Bustorff-Silva, C. A. Perez // J. Pediatr. Surg. - 1999. - Vol. 34, № 4. - P. 527-531.

[14] Berezin, S. Gastroesophageal reflux secondary to gastrostomy tube placement / S. Berezin, S. M. Schwarz, M. S. Halata // Am. J. Dis. Child. - 1986. - Vol. 140, № 7. - P. 699-701.

[15] Lasser M. S., Liao J. G., Burb R. S. National trends in the use of antireflux procedures for children. Pediatrics. 2006; 118: 1828-35. 